\title{
Aids in China: Discourses on Sexuality and Sexual Practices
}

The state's management of the epidemic both reflects and illuminates social contradictions

\section{Évelyne Micollier}

\section{(2) OpenEdition}

\section{Journals}

Electronic version

URL: http://journals.openedition.org/chinaperspectives/496

DOI: $10.4000 /$ chinaperspectives.496

ISSN: 1996-4617

\section{Publisher}

Centre d'étude français sur la Chine contemporaine

\section{Printed version}

Date of publication: 1 August 2005

ISSN: 2070-3449

\section{Electronic reference}

Évelyne Micollier, " Aids in China: Discourses on Sexuality and Sexual Practices », China Perspectives [Online], 60 | july - august 2005, Online since 29 November 2006, connection on 28 October 2019 URL : http://journals.openedition.org/chinaperspectives/496 ; DOI : 10.4000/chinaperspectives.496

This text was automatically generated on 28 October 2019

(c) All rights reserved 


\title{
Aids in China: Discourses on Sexuality and Sexual Practices
}

The state's management of the epidemic both reflects and illuminates social contradictions

\author{
Évelyne Micollier
}

\section{EDITOR'S NOTE}

Translated from the French original by Jonathan Hall

This article is the revised version of a paper presented at a conference organised by the Centre d'études sur la population et le développement (CEPED) - Laboratoire population-environnement-développement (LEPED) entitled "La santé de la reproduction confrontée au Sida : enjeux sociaux et comportementaux dans les pays du sud" (Reproductive health in the face of Aids - social and behavioural issues in southern countries), IRD-ANRS, Nogent-sur-Marne, France, November $22^{\text {nd }}-23^{\text {rd }}, 2004$.

1 The issues around the prevention of HIV/Aids and the management of epidemic risk have revealed a number of serious contradictions in Chinese society. They are also proving excellent as means by which the changing sphere of sexuality and the range of opinions and practices that these changes are bringing into being can be analysed and considered $^{1}$. As Alain Giami has explained in his inquiry into the causes and contexts of sexual behaviour", "the Aids phenomenon has given rise to new sets of problems in the field of sexuality. These affect the networks of partners and the notion of risk, and they denote a shift in the social construction of sexuality". Thus in response to the Aids epidemic, a certain remoulding of sexual behaviour takes place. Studies have shown that some modes of behaviour are retained at the expense of others, according to their effect on HIV transmission; and even from the range of practices not considered to be sexual, some are selected on the basis of the same criteria.

2 The theoretical perspective of this article will be informed by the constructivist approach, which has radically altered our understanding of sexuality by raising 
questions concerning the social and historical context in which it is produced ${ }^{3}$. One theory which has emerged from within this perspective is that of "sexual scripts", according to which sexuality can be defined as a series of actions, meanings and relationships which lay down the emotional and sexual outlets within broader social structures (living conditions, gender relationships, etc.). "Sexual scripts" include the idea of a "sexual culture", which is the consensual pattern of ideas linked to the sexual behaviour of a group, supported by a world outlook and ethical values concerning the nature and aim of sexual relations. This also involves an affective model of emotional states and moral principles aimed at institutionalising whatever is felt to be normal, necessary or collectively approved ${ }^{6}$.

In China, the history of epidemics of sexually transmitted diseases (STDs) shows that the way in which sexuality is managed has a greater impact than disease control measures or health education ${ }^{7}$. Nowadays, attempts by the state to control sexuality have become a matter of policy. The development of official strategies in the struggle against Aids reveals a progressive institutionalisation of preventive measures, and the takeover by the state of health initiatives originally launched by a network of organisations, mostly under the umbrella of the UN and international NGOs. This political takeover of the struggle against Aids has been accompanied by a whole official discourse aimed at controlling both sexual practices and all representations relating to sexual issues.

But, despite the political efforts on the part of official agencies, and the predominant pressure of family values and cultural traits inherited from the past, individuals are subject to many influences associated with globalisation and China becoming a consumer society. Consequent marked shifts in the sexual arena have been revealed by recent studies ${ }^{8}$ and by data from a nationwide report ${ }^{9}$. With regard to this report, Erwin J. Haeberle, the German sexologist who contributed towards its conception at the theoretical and methodological level, explains that "in general the results of large-scale quantitative surveys of sexual behaviour are foreseeable, insofar as they hardly vary from country to country. For example, the fact that a large majority of students (university undergraduates) see their sex education as too conservative, reveals reactions which are globally shared in our rapidly changing world. The results which show that a considerable number of individuals have had pre-marital sexual relations are also more or less universal"10.

5 Haeberle also emphasises that the Liu report, the first major quantitative survey of sexual behaviour, raises more questions than it answers, thus opening the way to further research into sexuality in China.

6 The ideological and behavioural models underlying individual sexual behaviour are transmitted by messages from the family and the state, relayed by the schools and family planning organisations. Anything new in such messages is due to the triumph of consumerism, and economic and cultural globalisation. Thus three separate systems of representation and practice co-exist within contemporary Chinese society, generating tensions at the level of values, behaviour and acts. The first system arises from the manifold and constantly evolving Chinese tradition itself ${ }^{11}$. The second was introduced by Marxist ideology and fed into the project for building a socialist society. And the third can be attributed to a global model which affects China as much as the rest of the world. 
7 This article is divided into three sections. The first gives an analytical overview of current scientific literature, and of the available data concerning sexual behaviour and its representations. The second deals with governmental action and pronouncements, insofar as they concern the dynamics of the Aids epidemic and the risks of sexual transmission. And the third analyses the state's attempts to control sexuality within a historical perspective. We should note from the start that the very existence of the works referred to in the first part is itself a sign of change. A number of them are the outcome the government's need for expertise and information to support their activities in the fields of health, sex education and family planning. Despite being controversial, these works have received official support.

Sexuality in a changing ChinaReports on sexuality, and other studies : a shift towards official acknowledgment of the problems

8 Amid the studies of sexuality there are two distinct trends; the first consists of the large quantitative studies which roughly follow the model of the Kinsey report ${ }^{12}$, and the second consists of more nuanced studies which make use of qualitative data as their basis. The critical analyses of the national report on sexuality published in 1992 (written by Liu Dalin, often referred to as the Chinese Kinsey) throw considerable light on the existence of a wide range of sexual discourses. At the time when Liu Dalin was drawing his quantitative studies together in 1989-1990, the American Kinsey report was translated into Chinese by the sociologist Pan Suiming, director of the research institute for gender and sexuality at the sociology department of the People's University in Peking. According to Pan himself, he made his translation available to Liu who then took the Kinsey report as his model ${ }^{13}$.

Unlike recent reports on sexuality in other countries, the Liu report is not directly concerned with the sexual transmission of HIV because in the early 1990s, when the survey was conducted, the risk of an Aids epidemic was being officially denied. However, STDs including Aids had already been identified as a problem linked to sexual behaviour, which called for social measures and health initiatives.

10 The Liu report is based on a survey of 20,000 selected individuals from 15 provinces ${ }^{14}$, organised by the Shanghai Centre for Sociology and Sexology founded in December $1988^{15}$. The survey covers four categories of people : two categories of youth (school and college pupils, university students), married couples, and those found guilty of sexual crimes $^{16}$. The goal was to identify problems related to individual sexuality, with particular attention to young people, to the control and management of sexual matters, and to the spread of STDs. The survey was conducted under the auspices of many public and private agencies, such as Chinese and multinational firms, mass organisations like the family planning associations, the federation of women, workers' trade unions, and state institutions like police departments and schools, all of whom distributed the questionnaires ${ }^{17}$.

11 The political and social climate in the late 1980s was favourable to the planning and implementation of such a project. Some doctors at the time, particularly Doctor Wu who headed the Academy of Medicine, and Professor Ruan of the University medical faculty ${ }^{18}$, both originally from Peking, were precursors in sexological research. Moreover, after a decade of openness and reform, the existence of sexual problems and of gaps in sex education were officially acknowledged, and they attracted a measure of public interest. 

in listing them below, I am keeping to the terminology used in the survey ${ }^{19}$. They were :

- 1. An increase in the number of love affairs between secondary and high school students. According to a survey conducted in Shanghai between 1985 and 1988, about 60\% of high school students, and a significant number of secondary students, were involved in love affairs.

- 2. An increase in pre-marital sexual relations. According to statistics from several hospitals, in 1986 there was a $16 \%$ increase in the number of pre-marital pregnancies and requests for abortion.

- 3. An increase in extra-marital sexual relations. Several surveys show that from the late 1980 s onwards, the number of divorces on the grounds of adultery was between $25 \%$ and $40 \%$ of the total number ${ }^{20}$.

- 4. An increase in the number of cases of sexual incompatibility between married partners. In Shanghai in 1984, this was the grounds for $24 \%$ of all divorces. By 1986, this rate had almost doubled $(45 \%)^{21}$.

- 5. A growth in sexual offences. According to the Shanghai statistical bureau, the number of reported rapes increased fourfold between 1979 and 1983, while the age of the rapists fell. Gang rapes became more numerous, more violent, and more premeditated ${ }^{22}$.

- 6. A growth in the sex trade. Under the reforms, the sex trade has expanded from the coastal regions into the towns and villages of central China. In 1987, the number of prostitutes arrested was 240 times greater than in 1979.

- 7. The spread of STDs, including Aids. In the late 1980s the infection rate of STDs rose by $300 \%$ annually, and the first case of Aids was reported in 1985.

- 8. An increase in the number of pornographic publications. Periodic campaigns to eradicate pornography testify to its widespread use.

- 9. Increasing confusion in the understanding of sexuality. In China "feudal ideas" about sexuality still have a certain influence. Moreover, ideas from the capitalist West have been spread over the last century, to which have been added communist doctrines from the post-1949 period, and these have undergone further alterations by the latest fashions and behaviour imported from Europe and the United States. Such an ideological mixture has led in a perfectly predictable manner to the confusion of the younger generations. China is still seeking a new rational and healthy way of looking at sexuality ${ }^{23}$.

- 10. Family planning is experiencing great difficulties. Its aim is to keep the population levels under 1.2 billion but, given the difficulty in educating people and applying family planning policies in backward regions, there is a large likelihood of failure. This is yet another reason why the government and the people should recognise the importance of sex education.

Official pronouncements stress "the historical necessity of facing these problems, and solving them, although it is difficult to acknowledge their existence, particularly that of the growing sex trade and the spread of STDs" ${ }^{24}$. One of the arguments put forward to stir the government into action, by making a link with social modernisation, suggests that the state of sexual relations is a reliable index of modernity ${ }^{25}$.

According to Judith Farquhar, the Liu report is part of a completed research initiative with predetermined results, which shows that it is a tool in the arsenal of a "national pedagogical strategy" ${ }^{26}$. She draws attention to the close links between its results and the pre-existing social programme underlying governmental intervention into education, health and sexuality. Its very title, which makes use of such terms as wenhua (culture) and wenming (civilisation), places the project within an ideology of national 
development ${ }^{27}$. The short preface on the questionnaire distributed to the participants is very significant in this respect: "Sexuality is a major component in human life, and it is intimately linked to the healthy development of young people, the harmonious happiness of married couples, and to social cohesion and stability. Nowadays, sexuality poses a number of problems, firstly because society itself has caused a number of sexual inhibitions, but also for other reasons. This research project has been set up to enable us to understand the situation, and to find ways of resolving the contradictions involved. It will be very important for our social development, which is why we are seeking your help and support" 28 .

William R. Jankowiak was the first to conduct an ethnographic enquiry into love and sexual behaviour in China (in Hohhot, the capital of Inner Mongolia). In particular he has shown how changes in daily life, above all in love and sexual relationships, are transforming traditional social relations. He has a very positive opinion of the Liu report because, in his view its authors attempted a comparison with other similar surveys conducted in Japan, the United States and Western Europe. Moreover, their data will be useful to other researchers, because they have focused on the sexual behaviour of men and women while carefully defining sexuality as a social construct ${ }^{29}$. Jankowiak emphasises the need to deal with people as both separate individuals and intersubjective social beings, this being an approach which he adopts in his own works.

Throughout the 1980s and 1990s, surveys based upon the model of the Kinsey report were carried out both in China and in other societies with a Chinese culture (Taiwan and Hong Kong), as they underwent a rapid process of socio-economic and cultural change. Chang Jui-shan ${ }^{30}$, who is a sociologist specialising in comparative sexuality and gender relations, has deplored the way in which a whole nexus of problems are often reduced to a matter of deciding whether any given society follows, or fails to follow, the sexual path taken by the West. She casts a critical eye at these "Chinese Kinsey reports" ${ }^{31}$, pointing to some of their omissions. According to her, they completely fail to answer the following questions, which take account of facts established by her own research :

- Why do school pupils in Hong Kong report more permissive sexual behaviour, while holding more conservative ideas than their counterparts in Taiwan?

- Why are university students in China more open to sexual experimentation than those in Hong Kong, whereas Hong Kong is more modern and Westernised?

- Why should China be undergoing a "sexual revolution" while Taiwan and Hong Kong are experiencing less drastic changes in sexual attitudes?

- Why do young Taiwanese proclaim their own sexual conservatism, asserting that they do not wish to become "depraved" like the Americans, whereas young people from the mainland think of their unrestrained sexuality as an aspect of their modernity?

17 In attempting to reply to these questions, Chang proposes a model with two distinct analytical levels. The first addresses the nature of sexuality itself, as defined by the norms of a cultural tradition; the second deals with the sexual practices emerging as a response to the different "infra-structures" which vary according to the historical period and the societies sharing the same culture. The first level allows for intercultural comparisons, and the second for comparisons within a culture.

She introduces some working hypotheses which the Kinsey-style reports do not take into account, i.e. in Hong Kong, the influence of Christianity and the British colonial past ; in Taiwan, a reinvented Confucian ideology in the service of the state, aimed at promoting the construction of a certain kind of national identity ; in China itself, a 
certain loss of bearings, together with doubts about values in the face of diverse ideologies and models of behaviour-in a society where certain sections of the population are experiencing a post-modern condition ${ }^{32}$.

In the reports modelled on Kinsey, there is no concern with identifying local constructions of sexuality ; their implicit point of departure is to investigate the degree of sexual permissiveness or repression in the culture or individual members, analysed on the basis of statistics dealing with a range of sexual practices. This enquiry, with its implicit reference to what Michel Foucault has called the "repressive hypothesis", situates these practices within a modern Western conceptualisation of sexuality. In the modern Western world, Freudian influence has placed sexuality at the centre of life, arguing that it becomes "socialised" as the self becomes progressively confirmed in its self-consciousness. In this respect, Foucault's point in his chapter on "the repressive hypothesis" ${ }^{33}$, is that sexuality is at stake in a conflict of powers and is inscribed within a dialectic of repression and liberation.

20 My approach-which refers to Chang's work and the questions she raises-is to take my distance from positivist perspectives and to consider these works as metadiscourses on sexuality. Whether Chang's perspectives are confirmed or not, and even if her methodology is contentious, her comparative approach nonetheless contains a challenge to existing Chinese studies on sexuality. All these intellectual productions bear witness to a process of "indigenising" so-called "objective" studies, which were originally designed for application in the West, Chang herself being a member of the "intellectual diaspora" ${ }^{34}$. In my view, Chang's critique of the way in which the Liu report takes Kinsey as its model, and especially its use of Foucault's repressive hypothesis and Freudian concepts of sexuality in elaborating the theoretical framework of the enquiry, is well founded. For example, when such concepts are used in a study drawing upon Chinese informants, their relevance, their methodological deployment in organisation of the questionnaires, and the way they inform the instructions to respondents, certainly raise debateable issues.

21 A similar controversy has arisen among researchers into sexual identity. Although such identities as "gay/lesbian/queer" currently enjoy a "globalised" status, they are actually the outcome of recent collective movements in Western societies, so the controversy concerns their relevance for Chinese societies ${ }^{35}$. Specialists in this field prefer to talk of "people who engage in homosexual practices", which places the emphasis on the categorisation of distinctive practices, rather than on identities ${ }^{36}$.

I would like to turn briefly to the pioneering study by James Farrer on the sexuality of young people in Shanghai. In his view, changes in the field of sexuality should be seen as more directly linked to the reforms, and to the transition towards a market economy and the consequent development of consumerism. By highlighting the dialectical relations between the sexual culture and the emergence of specifically consumerist institutions and practices, he emphasises the central factor of the market for any investigation into the sexual culture of Shanghai ${ }^{37}$. Farrer's ethnological study deals with the sexual culture (xing wenhua) of young Shanghai heterosexuals aged between 18 and 35, and covers their encounters, their sexual histories, and their public statements and opinions on the matter. He analyses how these social practices changed during the reform period between 1980 and 2000. The most widely held account of this sexual culture in transition is that of an "opening" towards a more "liberal" model under Western and Japanese influence, working through leisure pursuits, the media, and 
personal contacts ${ }^{38}$. This same historical account is carried over, albeit in a more nuanced fashion, into academic studies documenting the process of sexual globalisation ${ }^{39}$. Based on ethnographic observations in discotheques, Farrer emphasises that the social phenomenon of the "disco" (disike) is not so much the outcome of either a "localisation" or a subversion of global practices, as an active consumption and participation in a kind of sexual "cosmopolitanism", which he ascribes to the construction of a "super-culture" rather than to a "sub-culture".

In concluding this limited introductory survey of recent ethnological and sociological writing on sexuality, I would stress that sexology has become a distinct field of research in China since the reforms started. According to the sociologist Pan Suiming, there were over two hundred books on sexology in print in 1991, as compared with only six in 1979. The scientific discourse on sexology has introduced a neutral language for discussing sexual issues and sex education, making communication in this field easier ${ }^{40}$. It has linked the growing diversity, visibility and consequent increase in sexual activity, with numerous other factors. Of great significance here is the change in the living environment, that is, the changes in physical accommodation, with the abandonment of dwellings centred around a courtyard in favour of apartment blocks, where private living space is better separated from the collective. Thus, the lifestyle of families and individuals has been privatised, allowing for more intimacy and more openness in sexual expression, whereas in traditional society, the basis of sexual morality was vested in the stable and relentless control over the individual by the group ${ }^{41}$.

Neo-traditional discourses and representations of sexuality

The ancient body of sexual knowledge included the erotic arts, which were legitimated by medical or religious discourse and loosely identified as following Taoist or Confucian teaching. In this field, a key contribution was made by the pioneering work of Robert van $\mathrm{Gulik}^{42}$, which proposed an integral history from its origins until the end of the Ming dynasty (1644). According to Charlotte Furth ${ }^{43}$, this body of knowledge was first reinvigorated in the early twentieth century, when sexuality was reintroduced as a matter of public concern in the service of social modernisation, and the health of the nation was conceived in relation to the population's capacity for biological reproduction. Currently it is being remobilised once again, but now in order to show that in China sexuality is represented in ways quite different from those that prevail in the West.

An example of this is the work on homosexuality in China by Zhou Huashan, a Hongkong researcher and gay rights activist. Zhou quotes Mencius (+/-380-289 BCE), the "spiritual heir to Confucius" ${ }^{44}$, to argue that sexuality was not at the centre of individual life : "to feed oneself and to make love are natural things to which no great attention should be paid" 45 . Zhou uses this argument to explain how it happens that in China the great majority of people who engage in homosexual practices get married.

This revitalisation of the ancient "sexual culture" (in the sense of a "sexual lore") in the service of modernisation tinged with a degree of self-orientalising ${ }^{46}$, is to be found in both academic works and in everyday speech on sexual matters by members of chinese cultural communities themselves ${ }^{47}$. What should we make of their reinterpretations? For example, Paul E. Festa points out that in Taiwan nowadays, Viagra is included in the same therapeutic category which traditional medicine reserves for stimulants and aphrodisiacs. So a biomedical remedy is reappropriated and integrated into local categories which existed prior to its invention. 

existing with an "indigenised" biomedical conception, other conceptions inherited from local traditions and innovations underlie practices related to sexuality and/or reproduction. Particular events, such as menstruation, pregnancy, birth and the months after birth (zuo yi ge yue) are the foci of beliefs originating from traditional medicine or popular family cures, which still carry weight among Chinese populations ${ }^{48}$. For example, the month's confinement of women after giving birth, or the prenatal education of the unborn baby (tao jiao, education of the foetus), which clearly acknowledges the human "foetal condition" ${ }_{49}$, are still widespread, even virtually systemic practices in numerous regions, and among certain sections of the population ${ }^{50}$. These beliefs throw light on local ways of conceiving of women's sexual health.

These particular events mark the biological rhythms of life, and their significance is socially constructed. They are conceived as moments of vulnerability to disease, owing to the conjoined loss of blood (xue) and life force (qi). The various recommendations laid down by Chinese medicine, in its learned or its popular forms, show a preoccupation with educating people in disease prevention. They sometimes appear as measures for protecting women's health, particularly their sexual health, especially in view of the importance attributed to qi in the representation of bodies, life, the natural environment, and daily social existence ${ }^{51}$. Similarly, in sexual relations, the man is enjoined to avoid ejaculation, thus preserving the vital essence, the jing (sperm), in order to guard against the risk of disease linked to the loss of jing, and therefore of $q i$ (for the jing is a transformation of qi). Arguing against this view that the protection of women's health is their goal, other writers interpret these same recommendations, which prescribe the confinement and seclusion of women, in terms of male domination and gender-based social relations within patrilinear and local patriarchal family structures.

The development of Aids, state action, and the risks of sexually transmitted HIV ${ }^{52}$

In the Asia-Pacific region, 7.4 million people are said to be infected with HIV, out of whom 1.1 million were newly infected in 2003. This was far higher than in previous years ${ }^{53}$. The low rates of positive test results in many countries of the region are deceptive, because they mask local epidemics, particularly in the most populated countries in the world, India and China. Although the total rate remains low $(0.07 \%)$ corresponding to 840,000 people living with HIV and 80,000 with Aids in 2003, the epidemic is among the most urgent of public health problems. There are areas of high infection in certain regions, and within certain sections of the population. In some areas of Yunnan, Xinjiang and Henan, the proportion of infections through sexual contact is growing as is the number of infected women. Between 2001 and 2002, the number of people infected grew by $44 \%{ }^{54}$. According to the Chinese ministry of health, China entered a phase of rapid expansion of the epidemic in 1998. Most national and international experts believe that more than a quarter of a million people are infected. The Ministry of Health has established that by 2010 , ten million people could become infected if effective means of combating the disease are not put in place ${ }^{55}$.

Since 2003, positive test results have been reported in every province, autonomous region, and city, which shows the widespread reach of the epidemic. In addition, HIV infections are spreading throughout the population. Out of the six provinces where the epidemic situation is the most worrying, four are in the southern regions (Yunnan,

China Perspectives, 60 | july - august 2005 
Sichuan, Guangxi and Guangdong), the remaining two being Xinjiang (in the northwest) and Henan (in the central region). In Guangxi, to take one example, the rate of HIV infection among women sex workers rose from $0 \%$ in 1996 to $11 \%$ in 2000, demonstrating a high growth rate in infection through sexual contact ${ }^{56}$.

of all the reported carriers of HIV, $10 \%$ are adolescents. A nationwide survey by the health authorities has shown that $60 \%$ of young people are ignorant or ill-informed about the disease, and that about $21 \%$ know nothing about methods for preventing it.

The majority of people with positive test results were cases of blood infection-either through injecting drugs with contaminated needles or else through normal medical injections involving the use of infected blood, the latter being a consequence of the widespread market in blood ${ }^{57}$. Nonetheless, the number of infections through sexual contact has also risen exponentially. In 1997, the proportion of reported HIV infections through heterosexual contact was $5.5 \%$ of the total, and in 2002 it was $10.9 \%^{58}$. By 2004 this rate had reached $19.8 \%$, while the rate for homosexual contact was $11.1 \%$, giving an overall rate of $30.9 \%{ }^{59}$. Homosexuals constitute the third high-risk category for HIV infection after intravenous drug users and sex workers. However, the scale of the epidemic among homosexuals may be masked by the fact that $90 \%$ of homosexuals get married and have sexual relations with their partners, at least in order to have children ${ }^{60}$.

In the 1990s, the first phase of the epidemic was the consequence of drug users sharing infected needles, followed by heterosexual contact, which is a pattern identical to that of the epidemics in Thailand, Vietnam, Burma and southern China.

One factor in people's exposure to HIV is their internal and external (transnational) mobility, plus the integration of the economies of east and southeast Asia, which has given rise to uneven development and the emergence of areas of deprivation. The mobility of people involved in the sex industry (sex workers, clients, owners of the various premises involved, go-betweens, smugglers, drivers, police authorities etc.) is an additional risk factor.

In June 2002, the UNAIDS report identified other factors behind the spread of the epidemic, namely the dismantling of the public health system-excluding many from the system of care and prevention-and the heavy stigma attached to AIDS sufferers. Although the Ministry of Health undertook measures to restore the health system in the countryside in the late 1980s, it had already completely collapsed in the poorer regions. The Peking health authorities are aware of the problem, and are trying to find means of re-establishing access to quality health care for the majority of citizens. Unfortunately, their proposals often remain a dead letter in the localities, for in reality, the regional authorities do not always have the financial resources to set up high-cost measures ${ }^{61}$.

There is pressure from international agencies and international NGOs working in China to promote accurate risk assessments and awareness by all the different agents involved (officials, activists, local organisations, all those involved in the sex industry, families, adolescents and young adults, and medical personnel).

For example, even though the vulnerability of ethnic minorities is officially recognised nowadays, (owing more to the pressure from international governmental and nongovernmental agencies than to any real political will on the part of officialdom), protective measures are still not adapted to their specific needs. But pioneering studies 
were conducted following the World Conference of Women held in Peking in 1995, and at that time programmes of research and action concerned with women's and minorities' health issues were encouraged ${ }^{62}$.

The principal line of action consists in recommending an adherence to traditional practices for maintaining reproductive health, if they are compatible with the recommendations put out by the international agencies, and in rejecting those which lead to negative results or present an obstacle to the practical implementation of health programmes. The terms used to describe such practices and their practitioners recall the Maoist period and its embrace of an evolutionary mindset in characterising the minority peoples, along the same lines as the attitudes commonly held in the Soviet Union; the practices of such people are said to be "primitive", "outmoded", "out of date", etc. These aspects of government intervention testify to the continuity of current official discourse with the Maoist period, and are based on a social evolutionist outlook.

39 In 2004, significant changes in public policy finally gave clear evidence of the state's increased involvement when faced with the risk of an HIV epidemic. The most significant changes were the establishment of a national support structure (a new national Aids commission was set up by the State Council in February 2004, followed by the publication of Document No. 7 in March, which set out an overall plan of action), the endorsement of more reliable scientific knowledge, a more down-to-earth grasp of the dynamics of the epidemic, and a willingness to develop methods of treatment and care for people living with HIV. All this represented a considerable advance over the previous periods of denial. While the first person to test positive was detected in 1985, it was only in 1996 that a branch of UNAIDS was set up in Peking. Throughout the 1990s a growing awareness could be observed among government officials and activists engaged in the struggle against AIDS. This was followed by some activity, but their interventions were not applied nationally. Today all the organisations involved in the struggle, as well as the local, national and international agencies working on the spot in China, are being encouraged to co-ordinate their activities in order to improve their efficiency.

A diachronic overview of official attempts to manage sexual issues, and state intervention

There are ongoing debates concerning the question of sexual control through State interventionist programmes, and whether sexuality has always been an object of official concern. Some writers claim that there is indeed an underlying historical continuity, beneath the apparent sexual emancipation and profound shifts in the behaviour of the younger generation, and despite the way in which the market economy appears to have produced "a sexual revolution"63. Others have no doubt that the age of sexual control by the state is over, because factors like globalisation and the power of the market are beyond the control of the authorities ${ }^{64}$, which means that people's behaviour is not susceptible to attempts to educate them. Nevertheless, as Deborah Davis and Stevan Harrell insist ${ }^{65}$, the withdrawal of the state from many realms of daily life has coincided with its increased control over biological reproduction, through the policy of one child per couple and family planning ${ }^{66}$. But, to return to the lessons from Chinese history, a diachronic view clearly shows that the social issues surrounding the management of sexuality play a more important role than any political will to manage health issues more efficiently. There are historical sources 
testifying to state pronouncements and actions aimed at controlling sexual behaviour as early as the Han dynasty $(-200 /+200)$, which was the first of the major imperial dynasties ${ }^{67}$.

During the Republican era (1912-1949), women's sexuality was envisaged in reproductive terms, and it was believed that women did not experience any desire for sex itself. For example, when male homosexuality was forbidden, female homosexuality was simply denied, and consequently had no place in public discourse ${ }^{68}$. The normalisation of sexuality, rather than its repression, was a constant preoccupation during periods of intense nationalism, like that of the first Republic (following the fall of the Qing empire in 1911), when medical science stepped forward to become the rational guide to regulation ${ }^{69}$. Public discourse and representations of sexuality were marked by evolutionary, nationalist and scientific terminology, testifying to an epistemological shift from the Confucian terminology which had prevailed until the early twentieth century ${ }^{70}$. For the intellectual elites of the time, the proper control of sexual desire was the key to restoring the power of the nation and achieving the goal of modernisation $^{71}$.

The work of Harriet Evans on Maoist and post-Maoist China shows that since 1949 sexuality has always been a special target for government intervention. She analyses how such practices as pre-marital and extra-marital sex, births, marriage, prostitution and homosexuality have been categorised, and she describes the ways in which monogamy, celibacy, maternity, abortion and the menopause have been represented in the discourses concerning education and sexual health. Official discourses have made use of scientific knowledge for their own purposes, to legitimise the imposition of moral and sexual duties on women. For example, in the restrictive ideological climate of pre-reform China, women were encouraged to become exemplary wives and mothers, in the name of an essentialising view of women which saw them primarily in terms of their biological sex and reproductive goals ${ }^{72}$.

Other authors question Evans' views, arguing that in the post-Mao era there have been no official ideological pronouncements on women's sexuality, and this has left an open field of action and expression. For example, one critic writes : "the gap between official ideology and the dominant culture has deepened, and a number of subjects [hitherto passed over in silence] have been addressed in public... This is the sign of a separation between a more rigid official ideology and the greater fluidity in the dominant postMaoist cultural formation with regard to the normalisation and control of sexual culture" "73. The state has given up its imposition of rules on sexual behaviour and on other areas of private life, and nowadays official discourse limits itself to exhortations to improve the quality of marriage and strengthen the family: "Whereas the state still decides what pertains to the private or public spheres, it has abandoned a wide range of individual behaviour, such as the sexual, to the private sphere. In the realm of sexuality, men and women are able to engage in various departures from the norm which were forbidden under Maoism, without incurring any political repercussions. The era of an unquestioned moral order imposed by a political and cultural elite, in sexual and other matters, is well and truly over"74.

Indeed, in China under the reforms, the images of women and of sexuality have radically altered, with the emergence of a new ethos and a new behavioural model based on consumer satisfaction and the sway of the market. Faced with this change, the 
former official pronouncements have faded away. The authorities have come to tolerate this change largely because it serves national economic interests.

Another of Evans' critics focuses on the way she airbrushes the Cultural Revolution (1966-1976) out of her account ${ }^{75}$. During that period, official discourse promoted the revolutionary ideal of the androgynous worker, whose real identity was to be found outside his/her own sensual and sexual body. Such an ideal is in stark contrast with the other periods in the history of the People's Republic, when the differences between men and women were represented as essential.

Today young people between 10 and 24 represent $26 \%$ of the total population, i.e. 327 million people (according to the census for 2000), hence the importance of studies on the sexuality of young people who face the risk of HIV and Aids. Moreover, pre-marital relations are reported at somewhere between $44 \%$ and $91 \%$, according to recent statistics from the Chinese Family Planning Association ${ }^{76}$. The association's director emphasises that, in general, surveys do not take into account the sexual activities of unmarried persons or their knowledge of sexual matters. So programmes for promoting sexual health are not always aimed at unmarried young people, which leaves a gaping hole in attempts at sexual education and disease prevention.

A reading of sex education handbooks ${ }^{77}$ shows that their writers take masturbation and pre-marital relations to be secondary issues, whereas sexual morality, by contrast, occupies a key place $^{78}$. Sex education courses are still optional in educational institutions, being part of the biology courses with little concern with imparting life planning skills. Particular mention should be made of the experimental project by the China Family Planning Association which has produced handbooks for adolescent education in collaboration with the United Nations Population Fund ${ }^{79}$. This programme provides for the distribution of such books throughout China, and for the education of adolescents at the local level as far as possible, that is to say, as long as it is not blocked by the resistance of others (parents, teachers, or government representatives). Through the reformation of its sex education programmes, the state may be able to initiate further changes within the family because, while the family is above all the place where the young receive early training, it also provides a learning space for members of the older generations. Alongside the school and the workplace, the family is also a conduit for transmitting officially sanctioned messages, the family setting being the traditional and universally accepted structure through which normalising messages are communicated to women. It may well turn out to be the appropriate forum for health education initiatives, including those for the prevention and care of Aids and other STDs.

The development of sociological and ethnological research into sexuality has increased since 1990. This development reveals both a greater permissiveness in terms of practices and representations, and an increased tolerance in matters of sexual morality, when compared with the puritanical policies of Maoism. The risk of HIV spreading through sexual contact, and the growing numbers of people infected by STDs in general, have tended to favour the development of such studies. Certain members of the state apparatus, despite being the target of criticism from others, have shown themselves willing to acquire the knowledge which they need to define their priorities and undertake remedial action. The collective movement against Aids, initiated by international agencies, whether non-governmental or indirectly supported by governments like the so-called $\mathrm{GONGOs}^{80}$, has also been helpful in developing these 
research programmes ${ }^{81}$. Nonetheless, the state management of sexual matters and risks to health is still channelled through a set of evolutionist assumptions about modernisation and progress, in ideological continuity with the modernist and essentialising assumptions of Republican China. Official actions and pronouncements confirm this continuing trend, despite the pluralisation and globalisation of society. As the debate between Chinese and non-Chinese specialists in the social practices of sexuality clearly shows, there is an ongoing engagement of contradictory forces in place. This article has identified this process through focusing on changes in the practices of sexuality and on the ways in which it is discursively represented. The tensions and negotiated compromises between the different participants, and the contradictions at the symbolic level, such as those created by the hybrid discourses of urban youth, have not yet stabilised. For these reasons it is too early to make a lasting assessment of the viability of current state initiatives and their impact on individual behaviour.

\section{NOTES}

1. This article is based on surveys of the sex trade and the risks of HIV/Aids, conducted in 1997 and 1999, in mainland China (Shanghai, and Beihai in Guangxi province), and in Taiwan (Taipei), from an anthropological perspective (interviews, personal observations in places of regular commercial sexual activity, biographical accounts from women sex workers), cf. Evelyne Micollier (ed.) Sexual Cultures in East Asia : the Social Construction of Sexuality and Sexual Risk in a Time of Aids, London, Routledge Curzon, 2004.

2. Alain Giami, "De Kinsey au Sida : l'évolution de la construction du comportement sexuel dans les enquêtes quantitatives", Sciences sociales et santé, Vol. 9, No. 4, 1991, pp. 23-56.

3. See, for example, John H. Gagnon and William Simon, Sexual Conduct: The Social Sources of Human Sexuality, Chicago, Aldine, 1973 ; Jeffrey Weeks, Sexuality and its Discontents : Meanings, Myths, and Modern Sexualities, London, Routledge and Kegan, 1985.

4. Gagnon and Simon, op. cit. ; Simon and Gagnon, "Sexual Scripts", Society, Vol. 23, No.

1, 1984, pp. 53-60.

5. Jeffrey Weeks and Janet Holland (eds.), Sexual Cultures: Communities, Values, and Intimacy, London, British Sociological Association, 1996 ; Gilbert Herdt (ed.), Sexual Cultures and Migration in the Era of AIDS : Anthropological and Demographic Perspectives, Oxford, Clarendon Press, 1997.

6. Herdt, op. cit., p. 10.

7. Frank Dikötter, "La sexualité et les maladies sexuellement transmissibles en Chine : discours médical et représentations sociales", in Marie-Eve Blanc, Laurence Husson, and Evelyne Micollier (eds.), Sociétés asiatiques face au Sida, Paris, L'Harmattan, 2000, pp. 23-39.

8. Pan Suiming, "A sex revolution in current China", Journal of Psychology and Human Sexuality, No. 6, 1993, pp. 1-14 ; James Farrer, Opening Up : Youth Sex Culture and Market 
Reform in Shanghai, Chicago, University of Chicago Press, 2002 ; Gail Hershatter, "Sexing Modern China", in Gail Hershatter, Emily Honig, Jonathan N. Kipman, and Randall Stross (eds.), Remapping China : Fissures in Historical Terrain, Stanford, Stanford University Press, 1996, pp. 77-93 ; Xu Xiaoqun, “The Discourse on Love Marriage, and Sexuality in Post-Mao China : A reading of the Journalistic Literature on Women", Positions : East Asia Cultures Critique, Vol. 4, No. 2, 1996, pp. 381-414.

9. Liu Dalin, Ng Man-lun, Zhou Liping, and Erwin J. Haeberle, Zhogguo dangdaixin wenhua: Zhongguo liagwan lie 'xing wenming' diaocha baogao (Contemporary Chinese Sexual Culture : Report of the 'Sex Civilisation' Survey on 20,000 Subjects), Shanghai, Sanlian shudia, 1992.

10. Preface by Erwin J. Haeberle to Liu Dalin, Ng Man-lun, Zhou Liping, and Erwin J. Haeberle, Sexual Behavior in Modern China : Report on the Nationwide Survey of 20,000 Men and Women (English language edition by Ng and Haeberle), New York, Continuum, 1997, p. 11.

11. Here I adopt a dynamic approach to tradition, taking account of its ruptures and its continuities in the course of its history. I refer both to its "invention" (cf. Eric Hobsbawn and Terence Ranger [eds.], The Invention of Tradition, Cambridge, CUP 1983) and to its current reinvigoration. The latter can be analysed at two levels-at the social level, as the emergence of a "post-modern condition" (cf. Jean-François Lyotard, La Condition post-moderne, Paris, Minuit, 1979), and at the psychological level, as the development of a "contradictory consciousness" among certain members of society (cf. Matthew C. Gutmann, The Meanings of Macho: Being a Man in Mexico City, Berkeley, University of California Press, 1996, p. 15 ; Gutmann's concept is inspired by that of Antonio Gramsci).

12. Alfred Kinsey et al., translated into French as Le comportement sexuel de l'homme, Paris, Pavois, 1948, and Le comportement sexuel de la femme, Paris, Amiot-Dumont, 1953. 13. Private communiqué from Pan Suiming, 2005. We should recall that in China there are two sociological research institutes which have specialised in sexuality studies over the last twenty years, the one headed by Liu Dalin in Shanghai, and the other by Pan Suiming in Peking.

14. Heilongjiang, Liaoning, Peking, Tianjin, Shandong, Shanxi, Jiangsu, Shanghai, Zhejiang, Fujian, Guangdong, Henan, Sichuan, Xinjiang, and Ningxia.

15. Today this centre is no longer headed by Professor Liu Dalin. In his retirement he set up a museum of sexual culture (xing wenhua bowuguan) in Nanking Road, one of the major commercial streets of Shanghai. It was forced to close in 2001, three years after opening, under financial pressure because rents in that area had become prohibitive. Moreover, the advertising signs facing onto the street used the word "sex" (xing), which had been forbidden. Since then it has reopened in Tongli (Jiangsu). See Liu Dalin, Fushi yu chunmeng: Zhongguo yu Riben de xing wenhua bijiao (Age of levity and dreams of Spring : comparing the sexual cultures of China and Japan), Peking, Zhongguo youyi chuban gongsi, 2005.

16. This category included rapists, as well as everyone engaged in the sex trade (the workers themselves, go-betweens, procurers).

17. Liu mentions unforeseen difficulties obstructing the successful completion of this project after the events of 1989. These included financial difficulties, because of the restrictions on foreign aid to China, and the economic recession (Liu et al. 1997, p. 24). In addition, the nationwide campaigns against capitalism and obscenity did not make the surveyer's task any easier. Despite these obstacles, the project continued. 
18. Ruan Fangfu, Sex in China: Studies in Sexology in Chinese Culture, New York, Plenum Press, 1991.

19. Liu et al., op. cit., pp. 20-21.

20. Liu Dalin, Xing shehui xue (Sociology of Sex), Jinan, Shandong renmin chubanshe, 1986.

21. Liu, op. cit.

22. Liu, ibid.

23. Fan Minsheng, "Analysis of the Cause for the Resurgence of Sexually Transmitted Diseases", Shehui xue (Sociology), No. 12, 1990, p. 27.

24. Liu et al., 1997, p. 21.

25. Gail Hershatter, op. cit., p. 90.

26. Judith Farquhar, Appetites : Food and sex in post-socialist China, Durham, Duke University Press, 2002, pp. 226-227.

27. For a discussion of the relationship between these terms, see Anna Anagnost, National Past-Times : Narrative, Representation, and Power in Modern China, Durham, Duke University Press, 1997, p. 79, quoted by Farquhar, op. cit., 1997 : national culture is to be remodelled to serve a progressive civilising project along the lines of the advanced industrial societies in Asia and the West.

28. Liu et al., op. cit., 1992, p. 774.

29.William R. Jankowiak, Sex, Death, and Hierarchy in a Chinese City : An Anthropological Account, New York, Columbia University Press, 1993, p. 35.

30. Chang Jui-shan et al., "Pre-marital sexual mores in Taiwan and Hong Kong : two pathways to permissiveness", Journal of Asian and African Studies, Vol. 32, Nos. 3-4, 1997, pp. 265-287 ; Chang Jui-shan, "Scripting Extramarital Affairs : Marital Mores, Gender Politics, and Infidelity in Taiwan”, Modern China, Vol. 25, No. 1, 1999, pp. 69-99.

31. Chang Jui-shan, “Do we need 'Kinsey Reports' in Chinese Societies ? An Alternative Paradigm for the Study of Chinese Sexuality", Bulletin of Concerned Asian Scholars, Vol. 31 , No. 1, 1999, pp. 40-42.

32. This refers to the condition described by Lyotard, op. cit.

33. Michel Foucault, Histoire de la Sexualité 1 : La Volonté de Savoir, Paris, Gallimard, 1976, pp. 25-67.

34. Born in Taiwan, Chang obtained her doctorate at the University of Michigan and currently teaches at the University of Melbourne. On this idea of the "indigenisation" of anthropological knowledge in the face of globalisation, see Jacky Assayag and Véronique Bénéï (eds.), “Intellectuels en diaspora et théories nomades”, L'Homme, No. 156, 2000 ; Gregory Guldin and Zhou Daming (eds.), "Moving from Indigenization towards Globalization", Chinese Sociology and Anthropology, Vol. 33, No. 1, 2000.

35. As another sign of the day, it should be noted that a gay and lesbian studies class is taught by the sociologist Sun Zhongxin at Fudan University in Shanghai, see Howard W. French "Chinese University Takes A Topic Out of the Closet", The New York Times, September 17, 2005.

36. See, for example, Zhou Huashan (Chou Wah-shan), "Homosexuality and the Cultural Politics of Tongzhi in Chinese Societies", in Gerard Sullivan and Peter A. Jackson (eds.), Gay and Lesbian Asia: Culture, Identity, Community, New York, Haworth, 2001 ; Zhou Huashan, Tongzhi : Politics of Same-Sex Eroticism in Chinese Societies, New York, Haworth, 2000 ; Lisa Rofel, "Qualities of Desire : Imagining Gay Identities in China”, Gay Lesbian Quarterly, Vol. 5, No. 4, 1999, pp. 451-474 ; Sang Tze-lan D., The Emerging Lesbian : Female Same-Sex Desire in Modern China, Chicago, University of Chicago Press, 2003. 
37. James Farre, op. cit., p. 10.

38. Ibid., p. 11.

39. Dennis Altman, Global Sex, Chicago, University of Chicago Press, 2001 ; James Farrer, "Disco 'Super-Culture' : Consuming Foreign Sex in the Chinese Disco", Sexualities, Vol. 2, No. 2, May 1999, pp. 147-166.

40. Pan Suiming, op. cit., p. 5.

41. Ibid., p. 13.

42. Robert van Gulik, Sexual Life in Ancient China: A Preliminary Survey of Chinese Sex and Society from ca. 1500 BC to 1644 AD., Leiden, E.J. Brill, 1961.

43. Charlotte Furth, "Rethinking Van Gulik : Sexuality and Reproduction in Traditional Chinese Medicine”, in Christina K. Gilmartin, Gail Hershatter, Lisa Rofel, and Tyrene White (eds.), Engendering China: Women, Culture, and the State, Cambridge (Mass.), Harvard University Press, 1994, pp. 125-146.

44. I have borrowed this term from Anne Cheng. See her Histoire de la pensée chinoise, Paris, Seuil, 1997, p. 159.

45. Zhou Huashan, Beijing tongzhi gushi, Hong Kong, Xiangkang tongzhi yanjiushe, 1996 ; Zhou Huashan, Histoires de 'Camarades' : les homosexuels en Chine, Paris, ParisMéditerranée, 1997, p. 76.

46. This can also be detected in studies dealing with the indigenisation of Chinese studies. See also Liu's latest work, op. cit., 2005, which compares the "sexual cultures" (xing wenhua) of China and Japan through their erotic arts. Liu is also interested in erotic objects (see note 16).

47. Furth, op. cit.; Charlotte Furth and Ch'en Shu-Yueh, "Chinese Medicine and the Anthropology of Menstruation in Contemporary Taiwan", Medical Anthropology Quarterly, Vol. 6, No. 1, 1992, pp. 27-48 ; Paul E. Festa, “The Blue Whirlwind Strikes Below the Belt : Male Sexuality, Gender Politics, and the Viagra Craze in Taiwan", in Catherine S. P. Farris, Lee Anru, and Murray A. Rubinstein (eds.), Women in the New Taiwan : Gender Roles and Gender Consciousness in a Changing Society, New York, Sharpe, 2004, pp. 199-220.

48. See, among other works, those of Charlotte Furth, listed above.

49. This condition is not widely acknowledged in the different cultures of the world, as Luc Boltansky argues in his work La Condition foetale, Paris, Gallimard, 2004.

50. It is obviously difficult, and even misleading, to generalise in the complex and varied Chinese context.

51. For a survey of the meanings of qi, from the everyday to the esoteric, see my article, "Control and Release of Emotions in Qigong Health Practices", China Perspectives, No. 24, July-August 1999, pp. 22-30.

52. This section was originally the first part of my article, "Phénomènes de stigmatisation dans un monde chinois confronté au VIH-Sida : vers une collaboration entre réponses officielles et société civile", in L'Approche culturelle de la prévention et du traitement du VIH-Sida : stigmatisation et discrimination, Paris, UNESCO, special study No. 20, 2003, pp. 39-54.

53. UNAIDS, Report on the global AIDS epidemic, 2004, 236 pp. : summary.

54. Chen Shengli, Zhang Shikun, and Sydney B. Westley, "HIV/AIDS Awareness Is Improving in China", Asia-Pacific Population Policy, East-West Center, Research Program Populations and Health Studies, No. 69, 2004.

55. UNAIDS, HIV-AIDS : China's Titanic Peril 2001, 2002, 89 pp. 
56. UNAIDS press communiqué : “New UNAIDS Report warns AIDS Epidemic still in early phase and not levelling off in worst affected countries”, New York, July 2nd, 2002. 57. The contaminated blood sales drama was denounced by the international press in 2001 (Elisabeth Rosenthal, "AIDS and Corruption in a Poor Chinese Province”, International Herald Tribune, May 31st [New York Times, May 28th]) : the sale of contaminated blood products organised by mafia chiefs, a traffic which resulted in an explosion of HIV infections by transfusion in the central rural areas, particularly Henan. For the commercial organisation of this trade, its social and economic implications, and the responsibility of national and local authorities, see Pierre Haski, Le Sang de la Chine : Quand le silence tue, Paris, Grasset, 2005. Although the number of people reported to be infected with HIV through the trade in blood and plasma is still the largest group, this mode of transmission is not very significant in terms of future epidemic prospects, given that most of these infections occurred before 1996.

58. UNAIDS, A Joint Assessment of HIV/AIDS Prevention, Treatment, and Care in China, December 1st, 2003, 40 pp.

59. UNAIDS, A Joint Assessment of HIV/AIDS Prevention, Treatment, and Care, December 1st 2004, p. 30.

60. Pan Suiming, "Homosexual Behaviors in Contemporary China", Journal of Psychology and Human Sexuality, Vol. 7, pp. 1-17 ; Pan Suiming, "Male Homosexual Behavior and HIV-related Risk in China", in Peter Aggleton (ed.), Bisexuality and AIDS : International Perspectives, London, Taylor-Francis Group, Social Aspects of Aids Series, 1996, pp. 178-190 ; Zhou, op. cit., 1996, 2000.

61. Charlotte Cailliez, "L'effondrement du système de santé rurale", Perspectives chinoises, No. 47, 1998, pp. 38-45.

62. See for example, the following : Fang Tie (ed.), Chuantong wenhua yu xingyu jiankang (Traditional Culture and Reproductive Health), Yunnan shengyu jiankang yanjiu huibian (Yunnan Reproductive Health Research Association), Zhongguo shehui kexue chubanshe (China Social Sciences Press), 1997 ; Tao Chunfang and Xiao Yang (eds.), Zhongguo funü shengyu jiankang yanjiu (Research on Women's Reproductive Health in China), Xin shijie chubanshe (New World Press), 1995.

63. Harriet Evans, Women and Sexuality in China : Female Sexuality and Gender since 1949, New York, Continuum, 1997.

64. Xu Xiaoqun, op. cit., 1996 ; Farrer, op. cit., 2002.

65. Deborah Davis and Stevan Harrel, Chinese Families in the Post-Mao Era, Berkeley, University of California Press, 1993.

66. Stevan Harrel, "The Anthropology of Reform and the Reform of Anthropology : Anthropological Narratives of Recovery and Progress in China", Annual Reviews of Anthropology, No. 30, 2001, pp. 139-161.

67. Paul R. Goldin, The Culture of Sex in Ancient China, Honolulu, University of Hawaii Press, 2002.

68. Xu, op. cit., p. 406.

69. Frank Dikötter, Sex, Culture, and Modernity in China: Medical Science and the Construction of Sexual Identities in the Early Republican Period, London, Hurst, 1995, p. 2 and p. 10.

70. Ibid. p. 8.

71. Ibid. pp. 1-2.

72. Li Yinhe, Zhongguo nuxing de ganqing yu xing (Love and Sexuality of Chinese Women), Peking, Jinri zhongguo chubanshe, 1998. 
73. Xu, op. cit. p. 406.

74. Ibid. p. 407.

75. Elaine Jeffreys, review of Harriet Evans Women and Sexuality in China : Female Sexuality and Gender since 1949 (New York, Continuum, 1997), China Journal, Vol. 40, 1998, pp. 207-210.

76. Xinhua (New China News Agency), "Research Shows Premarital Sex Prevalent in China", (Statistics released by The Chinese Family Planning Association), October 10th, 2003.

77. Yao Peikuan, "The Study and Practice of Adolescent Sex Education in China", Shanghai, Shanghai kexue yuan, Shanghai Academy of Social Sciences Papers, Vol. 4, 1992, pp. 443-456 ; Yao Peikuan (ed.), Survey on Sex Education : The Report, Xuelin, Xuelin Publishing House, 1990 ; Yao Peikuan (ed.), Education for Adolescence, Guangxi Science and Technology Publishing House, 1989 ; Yao Peikuan (ed.), A Common Sense Reader for Adolescents, Shanghai, Shanghai People's Publishing House, 1988 ; Zhu Weibing (ed.), One Hundred Questions on Adolescence for Middle School Students, Shanghai, Shanghai Medical College Publishing House, 1988 ; She Jianhai, "Woguo dangdai qingchunqi xing jiaoyu yanjiu he shixian" (Research and practices of sexual education for contemporary Chinese youth), in Shanghai jiaoyu keyan (scientific research on Shanghai sex education), No. 1, 1988 ; Wu Jieping (ed.), Xing Yixue (Medical sexology), Wenxian, Kexue jishu chubanshe, 1988 ; Sports Hygiene Department of the National Education Commission, One Hundred Questions and Answers on Sex Education for Middle School Students, Peking, Beijing University Publishing House, 1988.

78. Liu Dalin, “The Development of Sex Education in China”, in Linda Jaivain (ed.), "Sex", Chinese Sociology and Anthropology, Vol. 27, No. 2, 1994-1995, pp. 10-36; see the tables comparing the contents of various handbooks in a diachronic perspective, Liu et al., 1997, p. 555 (introductory period : 1952-1978), p. 561 (promotional period, yearly from 1988 to 1990$)$.

79. Cf. Zhongguo jihua shengyu xiehui (China Family Planning Association/United Nations Population Fund-UNFPA), Qingshaonian rensheng jineng peixun zhinan (Guidebook for Adolescent Reproductive Health Life Planning Skills Training), Peking, 2003, and a handbook intended for trainers, Qingshaonian shengzhi jiankang gongzuozhi peixun zhinan (Guidebook for Training of ARH Trainers), Peking, 2003.

80. "Government-Organised Non-Government Organisation" is a term coined by Gordon White, Jude Howell, and Shang Xiaoyuan (eds.), In Search of Civil Society: Market Reform and Social Change in Contemporary China, Oxford, Clarendon, 1996. It is a form of social organisation unique to China (shehui tuanti), and it plays a mediating role between national and international institutions ; on such GONGOs involved in the struggle against Aids, see Micollier, op. cit., 2003, pp. 49-51.

81. Evelyne Micollier, “Acteurs de la mobilisation collective contre le Sida en Chine et solidarités transnationales : dynamiques locales et visibilité des groupes de défense des minorités sexuelles et sociales", in Fred Eboko, Frédéric Bourdier, Pierre Broqua, and Olivier Fillieule (eds.), "Mobilisations collectives face au Sida dans le monde : Translations internationales et dynamiques locales", Face à face : Regards sur la santé, No. 7, 2005, pp. 31-40, on-line review, www.ssd.u-bordeaux2.fr/faf 


\section{ABSTRACTS}

The issues that have taken shape around the need to prevent the spread of HIV/Aids, and to manage the risks of an epidemic, throw light on the pressing contradictions within Chinese society. They offer a very pertinent approach for analysis of current changes in the field of sexuality and to understanding the variety of its discourses and practices. The theoretical perspective of this article will be informed by a constructivist approach, since such approaches have radically altered our understanding of sexuality by raising questions about the social and historical contexts that surround it. In China the history of sexually transmitted disease (STD) epidemics shows that the ways in which sexuality is managed have a greater impact than disease control measures or health education.

Nonetheless, despite the political efforts on the part of official agencies, combined with the dominant pressures of family values and of "revitalised" cultural traits inherited from the past, individuals are subjected to the multiple influences associated with globalisation and China's transformation into a consumer society. Recent studies have revealed marked shifts in the expression of sexuality.

This article has three sections. The first gives an analytical overview of current scientific literature, and of the available data concerning sexual behaviour and its representation. The second deals with governmental action and pronouncements in relation to the dynamics of the Aids epidemic and the risks of sexual transmission. And finally, the third section provides a diachronic analysis of the state's management of sexual issues. 